\title{
Arborização urbana para mitigação das condições microclimáticas em Goiânia, Goiás ${ }^{1}$
}

\author{
Rhayssa Alessandra Weirich²; Francine Neves Calili3; Marina Morais Monteiro ${ }^{4}$; Bruno Bastos \\ Gonçalves $^{5}$; Carlos De Melo e Silva Neto ${ }^{6}$; Fábio Venturoli ${ }^{7}$
}

\begin{abstract}
Resumo: A arborização urbana pode influenciar desde fatores paisagísticos a microclimáticos, com efeitos ao bem estar humano. Sendo assim, o objetivo deste trabalho foi caracterizar a arborização urbana de dois diferentes setores de Goiânia, Goiás, Brasil e verificar como a arborização influencia o microclima da região. Analisaram-se dois trechos, de $1 \mathrm{~km}$ cada, em duas avenidas da cidade de Goiânia (av. Goiás e av. Planície). Em cada trecho realizou-se o censo das árvores e a medição das seguintes variáveis climáticas: temperatura do ar $\left({ }^{\circ} \mathrm{C}\right)$, umidade relativa do ar $(\%)$, velocidade do vento $(\mathrm{km} / \mathrm{h})$ e intensidade luminosa (lux). Utilizou-se análise descritiva com frequência absoluta e relativa das espécies de árvores, teste de Mann-Whitney (95\%) para comparar a abundância entre as espécies, Teste T (95\%) para comparação das variáveis microclimáticas entre áreas ensolaradas e sombreadas em cada uma das avenidas e por último uma análise dos componentes principais (PCA) e análise de correspondência (CCA) para verificação da influência das variáveis ambientais entre áreas ensolaradas e sombreadas. Nas áreas sombreadas pelas copas das árvores a temperatura do ar, intensidade luminosa e a velocidade do vento apresentaram valores mais baixos do que nas áreas ensolaradas, enquanto que a umidade relativa do ar se mostrou maior nesses ambientes do que nos que apresentavam ausência de árvores. A arborização contribui para melhoria das condições microclimáticas dos ambientes urbanos, influenciando positivamente o bem-estar humano nos centros urbanos.
\end{abstract}

Palavras - chave: Insolação; Conforto térmico; Ipês.

\section{Urban trees to mitigate microclimate conditions in Goiânia, Goiás}

\begin{abstract}
Urban trees can influence from landscape factors to microclimatic, affecting human well-being. This study had as objective to characterize two different sectors in Goiânia, Goiás, Brazil and to verify how urban trees influence the microclimate. Two different areas, $1 \mathrm{~km}$ long each one, in two avenues from the city (Goiás Av. and Planície Av.). In each area, a census from all trees was conducted and the following variables were measured: temperature $\left({ }^{\circ} \mathrm{C}\right)$, relative humidity $(\%)$, wind speed $(\mathrm{km} / \mathrm{h})$ and light intensity (lux). Descriptive analysis with absolute and relative frequency of tree species, Mann-Whitney (95\%) test for comparing abundance among species, T Test (95\%) for microclimate variables comparison among full sun and shaded areas in each one of the avenues and the last procedures were a principal components analysis (PCA) and a correspondence analysis (CCA) to verify the influence of environmental variables between full light and shaded areas. In areas shaded by trees crowns, temperatures, light intensity and wind speed showed lower values than shaded areas, while relative humidity showed higher values in these environments than in places without trees. Urban trees contribute to microclimatic conditions improvement in urban landscapes, positively influencing human well-being in urban centers.
\end{abstract}

Keywords: Insolation; Thermal comfort; Handroanthus sp.

\footnotetext{
${ }^{1}$ Recebido em 08.03.2015 e aceito para publicação como artigo científico em 08.11.2015.

${ }^{2}$ Engenheira Florestal. Universidade Federal de Goiás (UFG). E-mail: <rha.yssa@ hotmail.com>.

${ }^{3}$ Engenheira Florestal, Dra; Professora da Universidade Federal de Goiás (UFG). E-mail: <fncalil@ gmail.com>.

${ }^{4}$ Bióloga, M.Sc. Doutoranda do Programa de Pós-Graduação em Agronomia da UFG. E-mail: <marinammonteiro@gmail.com>.

${ }^{5}$ Biólogo, M.Sc. Doutoranddo Centro de Aquicultura da UNESP. E-mail: 〈goncalves.b.b@gmail.com>.

${ }^{6}$ Biólogo, M.Sc. Doutorando do Programa de Pós-Graduação em Agronomia da UFG. E-mail: <carloskoa@gmail.com>.

${ }^{7}$ Engenheiro Florestal, Dr; Professor da Universidade Federal de Goiás (UFG). E-mail: <fabioventuroli@ gmail.com>.
} 


\section{Introdução}

A maioria da população humana vive no meio urbano e precisa de condições que melhorem o convívio neste ambiente que, muitas vezes, apresentam-se em desconformidade ambiental (PIVETTA e SILVA, 2002; SILVA-NETO et al. 2013). A arborização pode atuar nessa melhoria do ambiente urbano, pois exerce funções importantes ligadas a aspectos ecológicos, estéticos e sociais. Do ponto de vista estético, a vegetação acrescenta beleza e emoldura ruas e avenidas, contribuindo para reduzir o efeito agressivo das construções que dominam a paisagem urbana, além de atuar na melhoria de fatores microclimáticos e biológicos, enquanto contribui para a satisfação do ser humano ao estar em contato com a vegetação (MILANO e DALCIN, 2000; BARROS et al., 2010).

Para Mascaró e Mascaró (2009), o sombreamento proporcionado por árvores, que possuem a capacidade de proteger o ambiente urbano da insolação, pode ser considerado a qualidade mais valorizada dentre os atributos que a vegetação pode oferecer. Dessa forma, atuando nos microclimas urbanos, a vegetação colabora para o controle da radiação solar, da temperatura e da umidade do ar, da ação dos ventos e da chuva e, consequentemente, influencia na redução da poluição atmosférica (MARTINI et al. 2013a; LEAL et al., 2015).

A influência que os plantios urbanos exercem nos microclimas das cidades está altamente interligada com os aspectos da vegetação. Dentre esses aspectos pode-se citar: o tipo de vegetação, porte, idade, período do ano, formas de associação entre os vegetais, e relação das plantas com as edificações e os recintos urbanos, entre outros (BRANCO, 2009).

Segundo Toledo-Filho e Parente (1988), é importante conferir à implantação da arborização urbana, heterogeneidade de espécies, pois assim, além de difundir a flora, se favorece a diversidade da fauna que influencia diretamente na manutenção do equilíbrio ecológico. Porém, para a implantação em meio urbano, existem características vegetais que podem ser indesejadas. Assim, é necessária a seleção de espécies para o plantio e que o mesmo não seja feito de forma arbitraria (BOBROWSKI e BIONDI, 2013).

Para uma seleção eficiente devem-se levar em consideração alguns aspectos importantes, como tolerância a poluentes, baixa aeração do solo, presença de odores ou mesmo de substâncias tóxicas, tempo de crescimento e longevidade da espécie, tamanho e coloração de flores e frutos, perfil de enraizamento, dimensão das copas e resistência de galhos e ramos, entre outros (TOLEDO-FILHO e PARENTE, 1988). Além disso, é preferível o uso de espécies nativas da região e resistentes a pragas e doenças, para que assim, se facilite o crescimento, a adaptação e o desenvolvimento das plantas (ANDREATTA et al., 2013).

A importância da arborização urbana para a capital do Estado de Goiás é evidente. Goiânia contém mais de 950.000 árvores de 328 espécies arbóreas e com índice de 0,79 árvores por habitante (PDAU, 2009). O município é conhecido como capital verde e possui 187 unidades de conservação que somadas totalizam 1.657 ha de áreas verdes urbanas (PDAU, 2009).

Segundo o Plano Municipal de Arborização urbana de Goiânia (2008), a arborização urbana do município iniciou-se na região Central da cidade, entre os anos de 1940 e 1950. Atualmente, por ser a arborização mais antiga, os plantios do setor central são os mais problemáticos.

Dentre os problemas está a abundância de espécies exóticas, como flamboyants (Delonix regia (Bojer ex Hook.) Raf.), ficus (Ficus microcarpa Linn.f.) e espatódea (Spathodea campanulata P. Beauv.), juntamente com a manguba (Pachira aquatica Aubl.). Estas espécies representam, hoje, em torno de $19 \%$ de todas as árvores plantadas em Goiânia. A implantação de alto número de indivíduos exóticos relaciona-se com a época em que os plantios foram realizados, período em que o conhecimento e valorização do Cerrado eram escassos e muitas vezes omissos (PDAU, 2009).

A arborização urbana não deve ser conduzida apenas em plantios de árvores e arbustos em ruas, avenidas, praças e parques. A implantação 
das árvores deve atingir objetivos de ornamentação com melhoria microclimática e a redução da poluição, fundamentada em critérios técnicos e científicos para viabilizar tais funções (CAVALCANTI et al., 2003; ANDREATTA et al., 2011). Sendo assim o objetivo deste trabalho foi inventariar a arborização urbana de dois diferentes setores de Goiânia e verificar como a arborização influencia nas variáveis microclimáticas da região.

\section{Material e métodos}

O estudo baseou-se em coleta de dados de variáveis microclimáticas: temperatura do ar $\left({ }^{\circ} \mathrm{C}\right)$, umidade relativa do ar $(\%)$, velocidade do vento $(\mathrm{km} / \mathrm{h})$ e intensidade luminosa (lux) e o censo de árvores, realizadas no período de 15 de março de 2014 a 31 de maio de 2014.

Área de estudo cidade de Goiânia, Av. Goiás e Av. Planície. A Av. Goiás é uma das três principais e mais antigas do município, inicia-se na Praça Cívica e termina na Avenida Nerópolis, apresentando extensão de $6,5 \mathrm{~km}$ e percorrendo diversos bairros da cidade. Dentre esses $6,5 \mathrm{~km}$, selecionou-se uma área de $1 \mathrm{~km}$, tendo seu início na Praça Cívica e término na Avenida Paranaíba (Figura 1). $\mathrm{O}$ trajeto de $1 \mathrm{~km}$ selecionado localiza-se no centro da cidade e é caracterizado por intenso comércio, trânsito e movimento de pedestres.

Por outro lado, a Avenida Planície apresenta $2,4 \mathrm{~km}$ de extensão e localiza-se a mais de $10 \mathrm{~km}$ do Setor Central, próximo à Universidade Federal de Goiás - Campus Samambaia, no Bairro Itatiaia. Assim como na Av. Goiás, na Av. Planície foi selecionada $1 \mathrm{~km}$ (Figura 2) para fins de representatividade deste estudo. Em ambos os trechos, da av. Goiás e Planície, as extremidades foram desconsideradas por sofrerem influencia de outras ruas.

$\mathrm{O}$ estudo foi realizado em duas avenidas da

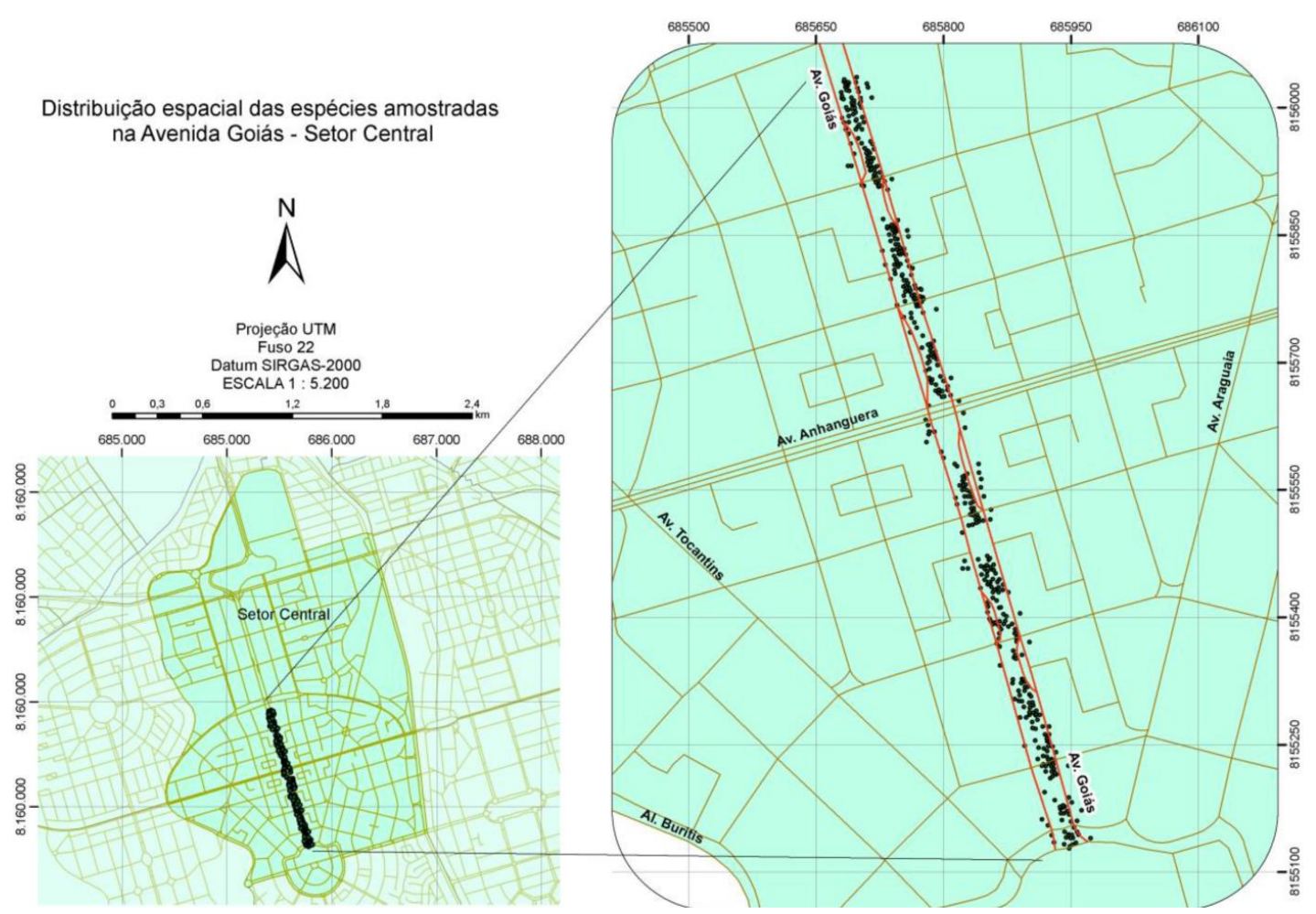

Figura 01: Distribuição espacial das espécies arbóreas da Avenida Goiás no setor Central, Goiânia, Goiás.

Figure 01: Spatial distribution of tree species of Goiás Avenue in the Central Sector, Goiânia, Goiás. 


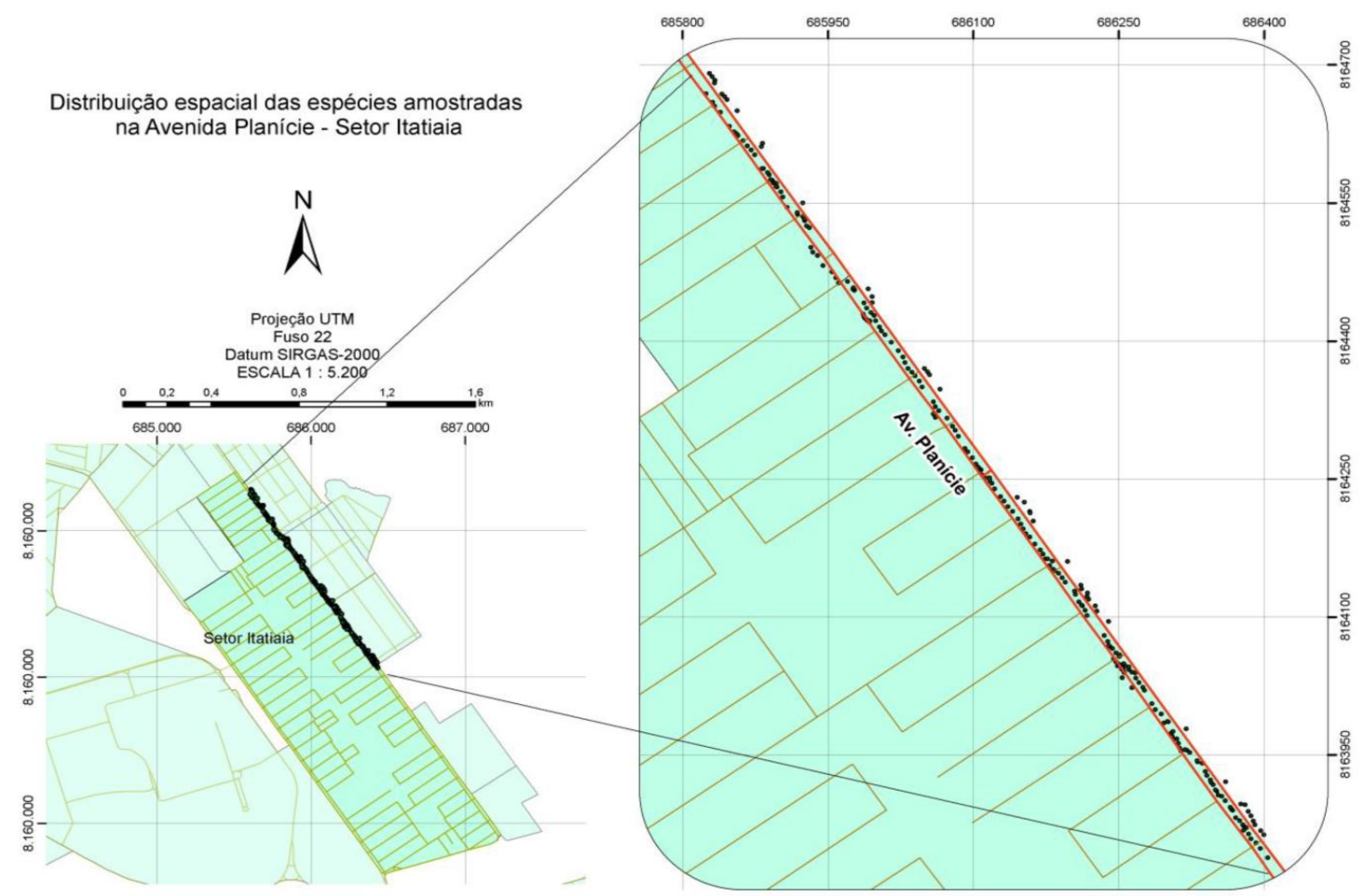

Figura 02: Distribuição espacial das espécies arbóreas da Avenida Planície no setor Itatiaia, Goiânia, Goiás. Figure 02: Spatial distribution of tree species in the Planicie Avenue in Itatiaia Sector, Goiânia, Goiás.

Censo das árvores

O censo das árvores foi realizado concomitantemente à coleta das variáveis microclimáticas. Cada indivíduo arbóreo teve sua espécie identificada com auxilio de chave de identificação botânica (PESTANA et al., 2011; SILVA-JUNIOR, 2012), e quando a identificação não foi possível no local, uma amostra da árvore foi coletada com tesoura de poda, para comparação com material do herbário da Universidade Federal de Goiás, em Goiânia.

As coordenadas geográficas foram demarcadas, com o auxílio de GPS. As avenidas estudadas apresentam duas pistas, sendo assim o censo foi realizado nas duas margens e no canteiro central (presente nos dois trechos selecionados de cada avenida) (adaptado de SILVA et al., 2005).

Mediação das variáveis microclimáticas

Com o auxílio da miniestação meteorológica (marca Speedtech modelo WM 300) e de um luxímetro (marca Instrutherm, modelo LD 300) foram medidas as seguintes variáveis climáticas: temperatura do ar $\left({ }^{\circ} \mathrm{C}\right)$, umidade relativa do ar $(\%)$, velocidade do vento $(\mathrm{km} / \mathrm{h})$ e intensidade luminosa (lux), definidas de acordo com Mahmoud (2011). As medições foram realizadas a partir das 9 horas da manhã até às 17 horas da tarde, sendo realizada a cada meia hora, totalizando 18 avaliações no dia.

O conjunto de medições foi realizado em nove diferentes locais ao longo das avenidas, escolhidos aleatoriamente. Em cada local, foram realizadas duas medições com intervalo de 30 minutos entre elas, considerando que cada medição é realizada em conjunto (pareada) na área com a presença e na área em ausência da arborização para verificar a influência das árvores na variação do microclima (Adaptado de MAHMOUD, 2011).

Análise estatística

Utilizou-se análise descritiva com frequência absoluta e relativa das espécies das avenidas 
Goiás e Planíce com comparação entre canteiro central e calçada. Procedeu-se também o teste de Mann-Whitney com significância estatística de 95\% entre abundância de espécies.

Para comparação das variáveis ambientais entre a av. Goiás e av. Planície foi realizado teste t pareado com significância estatística de 95\% entre áreas ensolaradas e sombreadas na Avenida Planície e Avenida Goiás para as características de radiação solar, temperatura do ar $\left({ }^{\circ} \mathrm{C}\right)$, umidade do ar $(\%)$ e velocidade do vento $(\mathrm{m} / \mathrm{s})$. Para verificar a influência das variáveis ambientais entre áreas ensolaradas e sombreadas foi realizado analise dos componentes principais (PCA) e análise de correspondência.

\section{Resultados e Discussão}

A análise concentrada nos canteiros centrais das duas avenidas estudadas não demonstrou diferença estatisticamente significativa em abundância e riqueza de espécies, sendo igual entre as calçadas e canteiro central da av. Goiás e av. Planície $(\mathrm{H}=1,22 ; \mathrm{p}=0,66)$ (Figura 03 e Tabela 01). As condições microambientais como radiação, temperatura, umidade relativa do ar e velocidade média do vento tendem a variar mais em um ambiente com menos árvores, de menor porte ou mais jovens, como é o caso da Avenida Planície.

Em relação à composição florística, a espécie arbórea mais comum, em ambas as avenidas, foi a Roystonea oleracea (Jacq.) O.F. Cook, conhecida como palmeira-imperial (Tabela 01). Em geral, palmeiras são bastante ornamentais e apropriadas ao paisagismo, e frequentemente são encontradas em viveiros por preços pouco acessíveis, dependendo do porte da planta e da espécie (BARROS et al., 2010), porém para a arborização urbana, estas palmeiras proporcionam pouca sombra.

Depois da palmeira imperial, as espécies com maior frequência foram, em ordem decrescente, Pachira aquatica Aubl. (munguba) e Handroanthus spp. (ipês), na Avenida Goiás e Licania tomentosa (Benth.) Fritsch (oiti) na av. Planície (Tabela 01). Tanto oiti quanto munguba são espécies arbóreas de grande porte e de origem Amazônica, sendo amplamente utilizada na arborização de Goiânia por proporcionarem grandes copas e extensas áreas sombreadas (PDAU, 2009). Já os ipês ocorrem de forma natural em diversas regiões do Brasil, inclusive no Cerrado goiano (SILVA-JUNIOR, 2012).

Além de Goiânia, a munguba pode ser encontrada na arborização de diversas outras cidades fora da Amazônia, por exemplo, Maringá (PR) (BLUM et al., 2008), Nova Iguaçu (RJ) (ROCHA et al., 2004), Campina Grande (PB) (DANTAS e SOUZA, 2004) e em Brasília (DF) (KURIHARA et al., 2005). Segundo Lorenzi (1998), a utilização daquela espécie em plantios urbanos se tornou comum e recomendada devido à fácil manutenção silvicultural da mesma.

O oiti também é comumente encontrado em outras cidades brasileiras, fora de seu ambiente de ocorrência natural. Almeida e Neto (2010) documentaram essa espécie como sendo a de maior ocorrência nas cidades de Colíder e Matupá (MT), Silva et al. (2002) a encontraram em Uberlândia (MG) e Silva-Filho (2002) em Jaboticabal (SP). Segundo Barros et al. (2010), a frequente ocorrência do oiti deve-se ao fato de que a mesma pode apresentar mais vantagens do que desvantagens quando introduzidas no ambiente urbano. Entre os pontos negativos destaca-se o grande porte que essa espécie tende a atingir, podendo prejudicar a fiação elétrica e telefônica presente na maioria das cidades brasileiras. Porém, segundo os mesmos autores, entre os aspectos benéficos que o oiti pode proporcionar destacam-se o ciclo perene que proporciona boa sombra e o fato de suas raízes não danificarem o calçamento.

Os ipês também são comumente utilizados em arborização urbana principalmente por ser considerado de grande exuberância no período da floração. $\mathrm{O}$ Handroanthus serratifolius (Vahl) S. O. Grose, em específico, apresenta outras vantagens quando introduzido no meio urbano, pois, segundo Carvalho (2003), essa espécie se adapta bem aos efeitos da poluição urbana. Apesar dos aspectos benéficos, os ipês já foram registrados provocando interferência em 
calçadas e redes elétricas (FARIA et al., 2007),

aspectos negativos para as cidades.

demonstrando assim também possuírem

Tabela 01: Espécies arbóreas encontradas na arborização urbana em Goiânia, Goiás (P - Passeio (nº indivíduos); C - Canteiro central ( $\mathrm{n}^{\circ}$ indivíduos); FR - Frequência relativa (\%)).

Table 01: Arboreal species found in the urban trees of Goiânia, Goiás ( $\mathrm{P}-$ Sidewalk $\left(\mathrm{n}^{\circ}\right.$ trees); $\mathrm{C}-\mathrm{median}^{\mathrm{s}}$ trip $\left(\mathrm{n}^{\circ}\right.$ trees); FR - Relative frequêncy (\%)).

\begin{tabular}{|c|c|c|c|c|c|c|c|}
\hline \multirow[b]{2}{*}{ Espécies } & \multicolumn{3}{|c|}{ Av. Goiás } & \multicolumn{3}{|c|}{ Av. Planície } & \multirow[b]{2}{*}{ Total } \\
\hline & $\mathbf{P}$ & C & FR & $\mathbf{P}$ & $\mathbf{C}$ & FR & \\
\hline Roystonea oleracea (Jacq.) O. F. Cook & 7 & 206 & 45,9 & 1 & 87 & 36,9 & 301 \\
\hline Pachira aquatica Aubl. & 48 & 6 & 11,6 & 1 & 2 & 1,2 & 57 \\
\hline Handroanthus spp. & 1 & 54 & 11,8 & 2 & 3 & 2,1 & 55 \\
\hline Licania tomentosa Benth. & 10 & 0 & 2,1 & 28 & 6 & 14,2 & 44 \\
\hline- & 5 & 11 & 3,4 & 2 & 5 & 2,9 & 23 \\
\hline Handroanthus serratifolius (Vahl) S. O. Grose & 0 & 21 & 4,5 & 0 & 0 & 0 & 21 \\
\hline Mangifera indica $\mathrm{L}$. & 2 & 0 & 0,4 & 2 & 16 & 7,5 & 20 \\
\hline Handroanthus roseo-albus (Ridl.) Mattos & 0 & 17 & 3,6 & 0 & 0 & 0 & 17 \\
\hline Delonix regia (Hook.) Raf. & 4 & 0 & 0,8 & 0 & 11 & 4,6 & 15 \\
\hline Terminalia catappa $\mathrm{L}$. & 0 & 0 & 0 & 2 & 12 & 5,8 & 14 \\
\hline Physocalymma scaberrimum Pohl & 0 & 14 & 3 & 0 & 0 & 0 & 14 \\
\hline Duranta repens $\mathrm{L}$. & 0 & 0 & 0 & 8 & 3 & 4,6 & 11 \\
\hline Jacaranda sp. & 0 & 11 & 2,3 & 0 & 0 & 0 & 11 \\
\hline Ficus benjamina $\mathrm{L}$. & 1 & 0 & 0,2 & 3 & 5 & 3,3 & 9 \\
\hline Murraya paniculata (L.) Jack & 8 & 0 & 1,7 & 1 & 0 & 0,4 & 9 \\
\hline Ficus microcarpa L.f. & 0 & 9 & 1,9 & 0 & 0 & 0 & 9 \\
\hline Schinus terebinthifolius Raddi & 0 & 8 & 1,7 & 0 & 0 & 0 & 8 \\
\hline Terminalia sp. & 0 & 8 & 1,7 & 0 & 0 & 0 & 8 \\
\hline Tecoma stans (L.) Juss. ex Kunth & 7 & 0 & 1,5 & 0 & 0 & 0 & 7 \\
\hline Tibouchina granulosa (Desr.) Cogn. & 0 & 0 & 0 & 6 & 0 & 2,5 & 6 \\
\hline Lagerstroemia indica (L.) Pers. & 2 & 0 & 0,4 & 0 & 3 & 1,2 & 5 \\
\hline Sapindus saponaria $\mathrm{L}$. & 0 & 0 & 0 & 4 & 0 & 1,6 & 4 \\
\hline Eucalyptus sp. & 0 & 0 & 0 & 3 & 0 & 1,2 & 3 \\
\hline Syzygium samarangense Merr. \& Perry & 0 & 0 & 0 & 3 & 0 & 1,2 & 3 \\
\hline Cocos nucifera $\mathrm{L}$ & 0 & 0 & 0 & 2 & 0 & 0,8 & 2 \\
\hline Ficus variegata Blume & 0 & 0 & 0 & 2 & 0 & 0,8 & 2 \\
\hline Inga laurina (S W.) Willd & 0 & 0 & 0 & 0 & 2 & 0,8 & 2 \\
\hline Lophantera lactescens Ducke & 0 & 0 & 0 & 0 & 2 & 0,8 & 2 \\
\hline Morus nigra $\mathrm{L}$. & 0 & 0 & 0 & 0 & 2 & 0,8 & 2 \\
\hline Spondias purpurea $\mathrm{L}$. & 0 & 0 & 0 & 0 & 2 & 0,8 & 2 \\
\hline Cassia sp. & 1 & 0 & 0,2 & 1 & 0 & 0,4 & 2 \\
\hline Anacardium occidentale $\mathrm{L}$. & 0 & 0 & 0 & 0 & 1 & 0,4 & 1 \\
\hline Clethra scabra Pers. & 0 & 0 & 0 & 1 & 0 & 0,4 & 1 \\
\hline Crescentia cujete $\mathrm{L}$. & 0 & 0 & 0 & 0 & 1 & 0,4 & 1 \\
\hline Machaerium sp. & 0 & 0 & 0 & 1 & 0 & 0,4 & 1 \\
\hline Persea americana P. Mill. & 0 & 0 & 0 & 0 & 1 & 0,4 & 1 \\
\hline Spondias dulcis Sol. ex Parkinson & 0 & 0 & 0 & 0 & 1 & 0,4 & 1 \\
\hline Annona sp. & 1 & 0 & 0,2 & 0 & 0 & 0 & 1 \\
\hline Poincianella pluviosa (DC.) L.P.Queiroz & 1 & 0 & 0,2 & 0 & 0 & 0 & 1 \\
\hline Psidium guajava $\mathrm{L}$. & 1 & 0 & 0,2 & 0 & 0 & 0 & 1 \\
\hline Total & 99 & 365 & - & 73 & 165 & - & 702 \\
\hline
\end{tabular}


A Avenida Goiás apresentou menor variação das variáveis microclimáticas. A intensidade luminosa, temperatura e velocidade do vento variam pouco nesta área, onde as árvores já estão mais desenvolvidas e tendem a manter condições de equilíbrio ecológico e fisiológico adequadas. Por outro lado, a umidade relativa do ar se apresentou com maiores valores na av. Goiás, reforçando o pressuposto de que a arborização pode melhorar as condições de equilíbrio em relação ao microclima (Figura 03 ).

A intensidade luminosa é diretamente ligada às diferentes situações na arborização, com a presença de árvores ou palmeiras, aspectos fenológicos das arbóreas, gerando ambientes ensolarados ou sombreados. Dentre os fatores que mostram maior influência nas áreas avaliadas, a intensidade luminosa está destacada por estar diretamente associada aos diferentes ambientes, sendo que a diferença da radiação solar entre áreas ensolaradas e áreas sombreadas é, em média, 93635 lux para av. Planície (interceptação de $99,96 \%$ da intensidade luminosa) e 75652 lux para av. Goiás (interceptação de $97,6 \%$ da intensidade luminosa) $(\mathrm{t}=-2,7 ; \mathrm{p}=0.01)$. Em decorrência das intensidades luminosas, a temperatura também varia entre os ambientes. A diferença da temperatura entre áreas ensolaradas e áreas sombreadas é em média $3,74^{\circ} \mathrm{C}$ para avenida Planície e $1,06^{\circ} \mathrm{C}$ para avenida Goiás $(\mathrm{t}=-5,59$; $\mathrm{p}=0,000)$.

A maior variação entre as temperaturas foi a encontrada às $11 \mathrm{~h} 30 \mathrm{~min}$ horas, em que a medição realizada a pleno sol foi de $33,8^{\circ} \mathrm{C}$, e à sombra foi de $27,2^{\circ} \mathrm{C}$; mostrando uma diferença de $6,6^{\circ} \mathrm{C}$. Para a umidade relativa do ar, a variação máxima entre os ambientes foi de 7,3\% sendo que na área a pleno sol foi de $51,7 \%$ e na área sob as copas das árvores foi de 59\%. A diferença da umidade do ar entre áreas ensolaradas e áreas sombreadas é em média $8,18 \%$ para a av. Planície e $2,92 \%$ na av. Goiás $(\mathrm{t}=4,428 ; \mathrm{p}=0,000)$. Já a diferença da velocidade do vento reduziu $1,77 \mathrm{~m} / \mathrm{s}$ para Avenida Planície e $0,97 \mathrm{~m} / \mathrm{s}$ para av. Goiás $(\mathrm{t}=-2,18 ; \mathrm{p}=0,044)$. A velocidade do vento apresentou valores maiores na área a pleno sol, padrão este explicado pelo fato das árvores atuarem como quebra-vento.

Em relação aos tratamentos (sombreadas e ensolaradas), estes estão associados principalmente a características de intensidade luminosa, sendo que essa variável ambiental explica $96,76 \%$ da variação dos tratamentos (na figura 04 e 05 como radiação), o que influência diretamente a temperatura.

As variáveis ambientais se dispuseram agrupadas para cada localidade, sendo que para a av. Goiás a variável mais afetada foi a umidade relativa do ar. Estas características, associada à avenida pode ser atribuída ao fato da arborização na região ser antiga, com árvores adultas que ocupam grande parte da área, influenciando de maneira eficiente o microclima local. Já para a Avenida Planície, a velocidade do vento foi mais afetada de acordo com a característica do local (sombreado e ensolarado). A arborização da av. Planície é considerada recente, quando comparada com as do centro da cidade, assim áreas ensolaradas (sem árvores) apresentam condições mais extremas, sendo que uma das primeiras características microclimáticas que é afetada é a velocidade do vento, uma vez que as árvores servem como quebra-ventos.

A incidência do vento pode diminuir as diferenças de temperatura e umidade relativa do ar entre as áreas sombreadas (arborizadas) e as ensolaradas. Quando há pouco vento, a temperatura local é afetada principalmente pela radiação solar, que será afetada de maneiras diferentes de acordo com uso e o tipo de solo, vegetação, topografia, altitude, etc. (GIRALT, 2006; MASCARÓ e MASCARÓ, 2009; MARTINI et al., 2013b).

Martini et al. (2013b) destacam as características das espécies arbóreas que podem afetar o microclima nas ruas. Espécies com poucas folhas ou que perdem as folhas em determinada época do ano proporcionam ambiente semelhante a áreas sem arborização. Já espécies com presença de folhas, durante todo o ano, proporiam um ambiente mais agradável, pois as folhas dificultam a chegada da radiação ao solo, resfriando a área (ANDREATTA et al., 2011). 

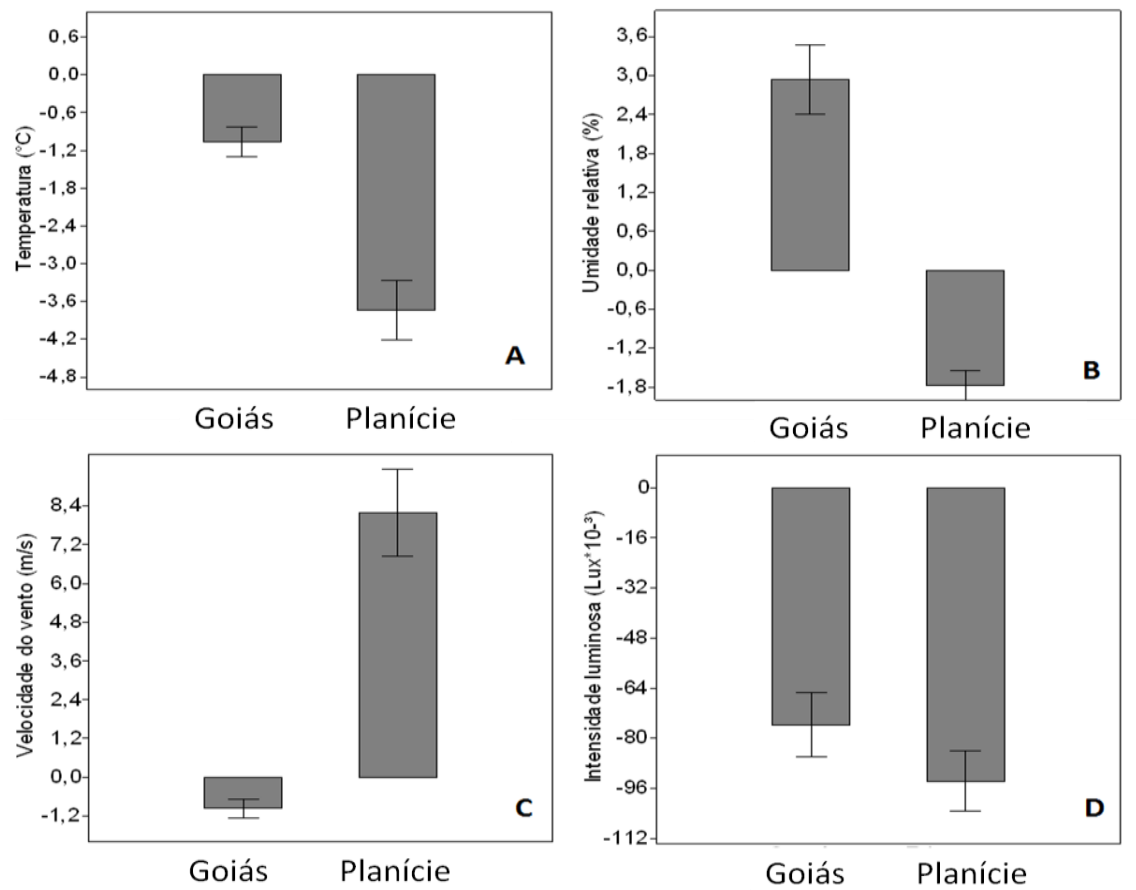

Figura 03: Comparação das diferenças entre variáveis microclimáticas em áreas ensolaradas e sombreadas na Avenida Planície e Avenida Goiás. A. Temperatura $\left({ }^{\circ} \mathrm{C}\right.$ ): Planície: $-3,74$ (valor absoluto: $31,14^{\circ} \mathrm{C}$ ); Goiás: $-1,06$ (valor absoluto: 29,54 ${ }^{\circ} \mathrm{C}$ ); $\mathrm{t}=-5,59 ; \mathrm{p}=0.000$. B. Umidade do ar (\%): Planície: 8,18 (valor absoluto: 52,77\%); Goiás: 2,92 (valor absoluto: 52,03\%); $\mathrm{t}=4,42 ; \mathrm{p}=0,000$. C. Velocidade do vento (m/s): Planície: $-1,77$ (valor absoluto: $2,27 \mathrm{~m} / \mathrm{s}$ ); Goiás: $-0,97$ (valor absoluto: $2,92 \mathrm{~m} / \mathrm{s}$ ); $\mathrm{t}=-2,18 \mathrm{p}=0,044$. D. Radiação solar: Planície: -93635 (valor absoluto: 96872,94 lux); Goiás: -75652 (valor absoluto: 77501 lux); $\mathrm{t}=-2,7 ; \mathrm{p}=0,01$.

Figure 03: Comparison of the differences between microclimates variables in sunny and shaded areas in the Planicie and Goias Avenue. A. Temperature $\left({ }^{\circ} \mathrm{C}\right.$ ): Planicie: $-3,74$ (absolute value: $31.14^{\circ} \mathrm{C}$ ); Goias: -1.06 (absolute value: $29.54^{\circ} \mathrm{C}$ ); $\mathrm{t}=-$ 5.59; $\mathrm{p}=0.000$. B. Air Humidity (\%): Planicie: 8.18 (absolute value: 52.77\%); Goias: 2.92 (absolute value: 52.03\%); $\mathrm{t}=4.42$; $\mathrm{p}=0,000$. C. Wind speed (m/s): Planicie: -1.77 (absolute value: $2.27 \mathrm{~m} / \mathrm{s})$; Goias: -0.97 (absolute value: $2.92 \mathrm{~m} / \mathrm{s}$ ); $\mathrm{t}=-2.18 \mathrm{p}=$ 0.044. D. Solar radiation: Planicie: -93635 (Absolute value: 96872.94 lux); Goias: -75652 (Absolute value: 77501 lux); $t=-$ $2.7 ; \mathrm{p}=0.01$.

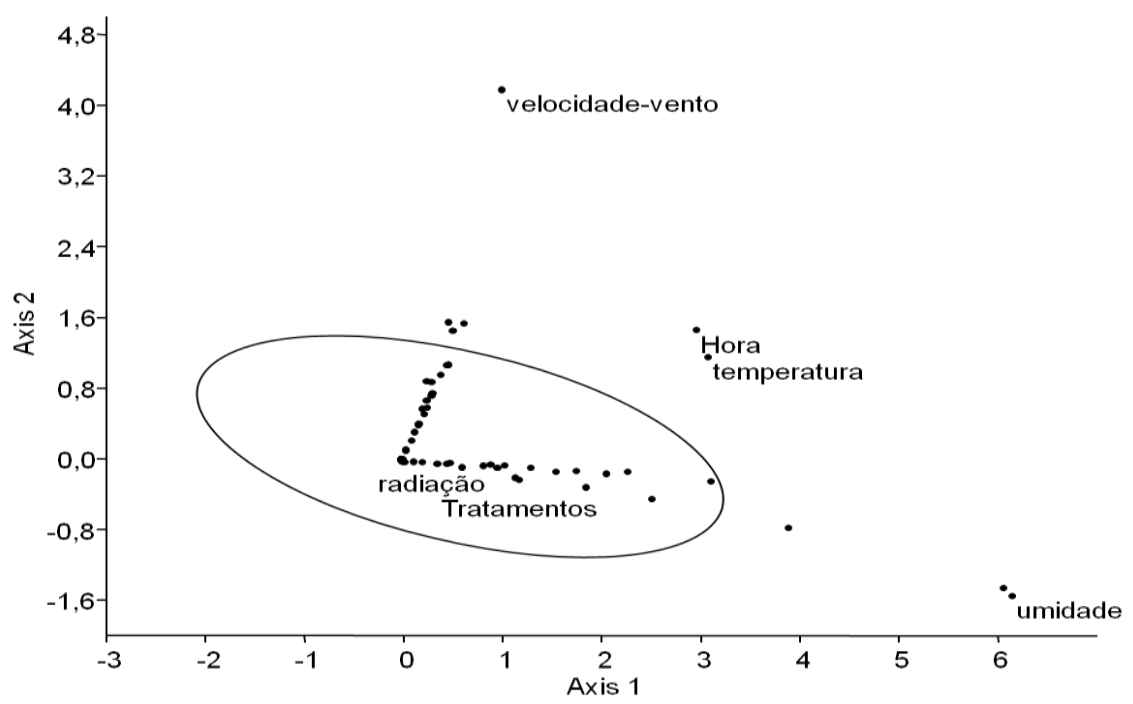

Figura 04: Analise de correspondência entre variáveis microclimáticas da Avenida Goiás e Planície e os tratamentos (ensolarado e sombreado) [elipse corresponde a 95\% dos dados; temperatura (Axis 1) e umidade (Axis 2) correspondem a $96,76 \%$ da variação].

Figure 04: Correspondence analysis between microclimate variables of the Goias and Planicie Avenue and the treatments (sunny and shaded) [ellipse correspond to 95\% of the data; temperature (Axis 1) and humidity (Axis 2) correspond to 96.76\% of the variation]. 


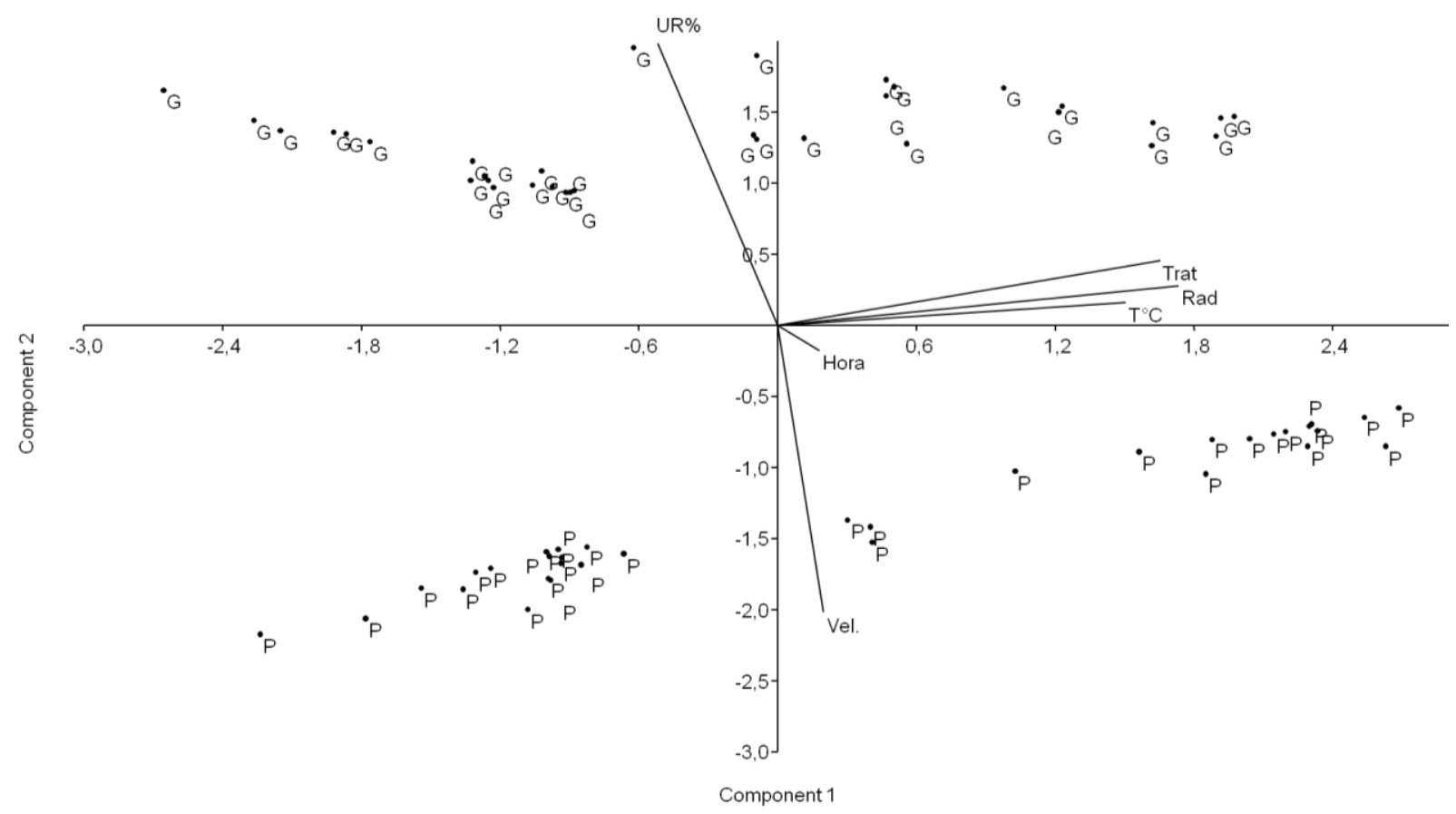

Figura 05: Analise dos componentes principais das variáveis microclimáticas da Avenida Goiás e Planície (Umidade do ar [Component 1] e temperatura do ar [Component 2] correspondem a 71,03\% da variação; Legenda: Trat - sombreado e ensolarado; rad - radiação; vel - velocidade do vento; UR\% - umidade relativa do ar; G - avenida Goiás; P - avenida Planície). Figure 05: Principal components analysis of the microclimate variables in the Goias and Planicie Avenues (Air humidity [component 1] and air temperature [component 2] corresponding to $71.03 \%$ of the variation; Subtitle: Trat - shaded and sunny.. rad - radiation; vel - wind speed; UR\% - Air relative humidity; G - Goias avenue; P - planicie avenue.

Dentre as árvores da av. Goiás, os ipês (Handroanthus spp.) são frequentes, e nesta espécie é comum a perda das folhas antes da floração, podendo alterar o microclima local. Durante o monitoramento das variáveis microclimática deste estudo, os ipês estavam todos com folhas e copas bem formadas, fator que provavelmente exerceu significativa influencia nos valores encontrados para as condições microclimáticas na Avenida Goiás.

Jochner et al. (2013) evidenciaram o efeito das características do microclima em áreas tropicais e temperadas nos eventos fenológicos de árvores em ambientes urbanos. Assim, tornase relevante verificar como os eventos fenológicos podem afetar o microclima urbano. Mesmo na av. Goiás, em que os ipês são frequentes na arborização, é desconhecido o efeito do estágio fenológico da planta no microclima na avenida, sendo relevante para futuros estudos.

\section{Conclusões}

- A arborização contribui para melhoria das condições microclimáticas dos ambientes urbanos (redução da temperatura e aumento da umidade relativa do ar);

- Nas áreas arborizadas, as variáveis microclimáticas, como temperatura, intensidade luminosa e velocidade do vento apresentaram valores menores do que nas áreas sem árvores enquanto a umidade relativa do ar é maior em ambientes com árvores.

\section{Referências}

ALMEIDA, D. N.; RONDON NETO, R. M. Análise da arborização urbana de duas cidades da região norte do estado de Mato Grosso. Revista Árvore, v. 34, n. 5, p. 899-906, 2010. 
ANDREATTA, T. R. et al. Análise da arborização no contexto urbano de avenidas de Santa Maria, RS. Revista da Sociedade Brasileira de Arborização Urbana, v. 6, n.1, p.36-50, 2011.

BARROS, E. F. S.; GUILHERME, F. A. G.; CARVALHO, R. S. Arborização urbana em quadras de diferentes padrões construtivos na cidade de Jataí. Revista Árvore, v. 34, n. 2, p. 287-295, 2010.

BLUM, C. T.; BARGO, M.; SAMPAIO, A. C. F. Espécies exóticas invasoras na arborização de vias públicas de Maringá-PR. Revista da Sociedade Brasileira de Arborização Urbana, v. 3, n. 2, 2008, p. 78-97.

BRANCO, L. M. B. C. Microclimas urbanos no Plano Piloto de Brasília: o caso da superquadra 108 Sul. 2009. 146 f. Dissertação (Mestrado em Arquitetura e Urbanismo) Universidade de Brasília, Brasília. 2009.

BOBROWSKI, R.; BIONDI, D. Espécies não tradicionais e espécies indesejáveis na composição da arborização de ruas. Enciclopédia Biosfera, v. 9, p. 1293-1304, 2013.

CARVALHO, P. E. R. Espécies arbóreas brasileiras. Vol. 1. Brasília: Embrapa Informação Tecnológica, 2003,1039 p.

CAVALCANTI, M. L. F. et al. Identificação dos vegetais tóxicos da cidade de Campina GrandePB. Revista de Biologia e Ciências da Terra, v. 3, n.1, p. 1-13, 2003.

DANTAS, I. C.; SOUZA, C. M. C. Arborização urbana na cidade de Campina Grande - PB: Inventário e suas espécies. Revista de Biologia e Ciências da Terra, v. 4, n. 2, 2004.

FARIA, J. L. G.; MONTEIRO, E. A.; FISCH, S. T. V. Arborização de vias públicas do município de Jacareí - SP. Revista da Sociedade Brasileira de Arborização Urbana, Piracicaba, v. 2 , n. 4 , p. 20-33. 20, 2007.

GIRALT, R. P. Conforto térmico em espaços públicos abertos na cidade de Torres - RS. 2006. 238 f. Dissertação (Mestrado em Arquitetura) - Universidade Federal do Rio Grande do Sul, Porto Alegre, 2006.

JOCHNER, S. et al. Using phenology to assess urban heat islands in tropical and temperate regions. International Journal of Climatology, v. 33, p. 3141-3151, 2013.

KURIHARA， D. L.; IMAÑA-ENCINAS，J.; PAULA, J. E. Levantamento da arborização do campus da Universidade de Brasília. Cerne, v. 11, n. 2, p. 127-136, 2005.

LEAL, L.; BIONDI, D.; BATISTA, A. C. Extremos de temperatura na cidade de Curitiba PR e estratégias para amenização microclimática. Enciclopédia Biosfera, v. 11, p. 3137-3150, 2015.

LORENZI, H. Árvores brasileiras. Nova Odessa: Plantarum, 1998. 2 v.

MAHMOUD, A. H. A. Analysis of the microclimatic and human comfort conditions in an urban park in hot and arid regions. Building and Environment, v. 46, p. 2641-2656, 2011.

MARTINI, A.; BIONDI, D.; BATISTA, A. C. Influência da arborização de ruas na atenuação dos extremos meteorológicos no microclima urbano. Enciclopédia Biosfera, v. 9, p. 16851695, 2013a.

MARTINI, A.; BIONDI, D.; BATISTA, A. C. Variação diária e estacional do microclima urbano em ruas arborizadas de CuritibaPR. Floresta e Ambiente, v. 20, n. 4, p. 460469, $2013 b$.

MASCARÓ, L.; MASCARÓ J. J. Ambiência urbana. 3rd ed. Porto Alegre: +4 Editora; 2009.

MILANO, M. S.; DALCIN, E. Arborização de 
vias públicas. Rio de Janeiro: Light, 2000. 206 p.

PESTANA, L. T. C.; ALVES, F. M.; SARTOR, Â. L. B. Espécies arbóreas da arborização urbana do centro do município de Campo Grande, Mato Grosso do Sul, Brasil. Revista da Sociedade Brasileira de Arborização Urbana, v. 6, n. 3, p. 01-21, 2011.

PDAU. Plano diretor de arborização urbana de Goiânia. Goiânia: AMMA, 2008, 134 p.

ROCHA, R. V.; LELES, P. S. S.; OLIVEIRA NETO, S. N. Arborização de vias públicas em Nova Iguaçu, RJ: o caso dos bairros Rancho Novo e Centro. Revista Árvore, v. 28, n. 4, p. 599-607, 2004.

SILVA, A. G.; GONÇALVES, W.; LEITE, H. G. Comparative Study of the Random and Systematic Sampling Procedures in Urban Arborization Inventories. Natureza \& Desenvolvimento, v. 1, n. 1, p. 67-73, 2005.

SILVA, E. M. et al. Estudo da arborização urbana do Bairro Mansur na cidade de Uberlândia-MG. Caminhos de Geografia, v. 3, n. 5, p. 73-83, 2002.

SILVA-FILHO, D. F. Cadastramento informatizado, sistematização e análise da arborização das vias públicas da área urbana do município de Jaboticabal, SP. 81f. Dissertação (Mestrado em Geografia). Universidade Estadual Paulista, Jaboticabal, 2002.

SILVA-JUNIOR, M. C. 100 árvores do Cerrado - sentido restrito: guia de campo. Brasília, Rede de Sementes do Cerrado, 304 p, 2012.

SILVA-NETO, C. et al. Ocupação de áreas de preservação permanentes dos canais fluviais em ambiente urbano do município de Jataí - GO.

Revista Percurso, v. 5, p. 73-89, 2013.
TOLEDO-FILHO, D. V.; PARENTE, P. R. Arborização urbana com essências nativas. Boletim Técnico do Instituto Florestal, v. 42, p.19-31, 1988. 